\title{
Chlamydia prevention in Sweden-A case study of potential key factors in successful response
}

\author{
Charlotte Deogan ${ }^{1}$, Cecilia Moberg $^{2}$, Lene Lindberg $^{1}$, Anna Månsdotter $^{1}$ \\ ${ }^{1}$ Department of Public Health Sciences, Karolinska Institutet, Stockholm, Sweden; ${ }^{*}$ Corresponding Author: charlotte.deogan@ki.se \\ ${ }^{2}$ Department of Neurobiology, Care Science and Health, Karolinska Institutet, Stockholm, Sweden
}

Received 12 June 2012; revised 15 July 2012; accepted 23 July 2012

\begin{abstract}
Background: After a continuous increase of Chlamydia trachomatis (chlamydia) in Sweden, a general reduction in reported cases was seen in 2009. However, the number and decrease of chlamydia cases varied largely between geographical regions. Aim: The aim of the present study was to identify potential key factors of successful regional prevention of chlamydia and other sexually transmitted infections (STIs). Methods: A multiple case study was performed including seven Swedish counties. Data was collected via surveys and interviews with key informants, county council registry data, survey data on condom use, and surveillance data on reported cases of chlamydia. In a case comparison, factors of prevention structure and prevention activities were identified and rated as strengths or weaknesses compared to standard preventive measures. Potential key factors were identified by examining prevention strengths corresponding to high condom use and decrease of chlamydia cases. Results: Differences were found in prevention structure and activities across counties. Identified potential key factors were; adequate investments in STI prevention, suitable organizational structure, strong leadership, managing regional STI-networks, research connection, multiple local collaborations with health care and community, high testing coverage and strategic risk approach. Conclusions: This study shows that greater consideration to structural factors of chlamydia prevention may benefit the outcomes of STI-prevention activities.
\end{abstract}

Keywords: Chlamydia; STIs; Prevention; Prevention Structure; Case Study

\section{BACKGROUND}

The most frequently reported sexually transmitted in- fection (STI) in several countries including Sweden, is Chlamydia trachomatis (chlamydia). Chlamydia is most common among 15 - 29 years old, who account for $89 \%$ of all Swedish cases (2010). The number of reported cases increased steadily from 1997 onwards and reached a peak of approximately 47,000 reported cases in 2007 (of which 57\% were female) [1]. Since then, a reduction has taken place with considerable regional differences [2], which suggest that the preventive response differs across geographical regions.

In 2009, the Swedish National Board of Health and Welfare developed a new Action Plan for Chlamydia Prevention 2009-2014 focusing on adolescents and young adults [2]. The national action plan (NAP) generally aimed to strengthen prevention with inter-sectorial collaboration and a mix of strategies. In Sweden, County Medical Officers (CMO) are responsible for the prevention and control of communicable diseases in each of Sweden's 21 counties and regions, whereas STI-coordinators are responsible for the particular coordination of preventive efforts of STI at the regional level. The NAP recommendations for the regional areas focus on improved counseling and partner tracing and increased availability and accessibility to health care services. Furthermore, schools and youth centers are mentioned as the main arenas for effective prevention, and uniform communication and information is underlined. To enable a successful preventive result, the NAP emphasizes the importance of effective collaboration between sectors and arenas as well as improved interaction within the health care sector [2].

Several studies have explored possible risk factors for acquiring a STI. Strong risk factors for chlamydia and other STIs include a young age at first sexual intercourse, multiple lifetime sexual partners, and a history of other STIs. Furthermore, health risk behaviours such as smoking, drinking and substance use have shown to affect the risk of STIs by association with sexual risk behaviour [3-5].

The evidence base of effective STI-prevention is limited. Reviews have identified some characteristics of 
effective interventions [6,7] but sufficient evidence for policy and guidelines is still lacking. A study from Australia on HIV/AIDS showed that cross-sectional partnerships or collaboration, commitment and active involvement of all key stakeholders and favourable resource allocation are key factors of successful prevention [8]. Other Australian studies emphasize adequate allocation of resources as critical for effective prevention of HIV [9] and stress the importance of policy and prevention strategies regarding different patterns of spread of disease [10]. Collaboration, competencies in the organization and clear leadership have also been further described as important factors for improved HIV prevention services [11] as well as availability and accessibility to information, health care, testing and counseling [12,13]. Regarding chlamydia, more women than men are diagnosed because of higher testing rates among women [1]. Thus, targeting men to get tested could be of particular importance. Quality assurance regarding staff qualification and allocated time has been shown to determine the effectiveness of partner tracing [14]. A gender consideration in this context is that more men than women are diagnosed through the partner tracing procedure. Moreover, consistent use of behavioural counseling may potentially have an effect on sexual attitudes, $[13,15]$ and has been found to promote healthy behaviors [16] as well as reduce maladaptive behaviors such as HIV risk taking [17]. Condom is still the only contraceptive method that provides protection against HIV and other STIs. Free distribution or low-cost provision of condoms in combination with information, and education or counseling may be an effective way to reduce chlamydia, considering the price sensitivity of the target group [18,19].

In summary, the evidence base of successful STI prevention entails a range of activities aiming to promote sexual- and reproductive health by reduced risk behavior and increased awareness, testing and condom use. Although most of the evidence presented above is included as recommendations in the NAP, comprehensive knowledge on the implementation at the regional level is lacking and there is insufficient understanding of the effectiveness of different components in the prevention mix.

\section{Aims}

The overall aim of the present study was to identify potential key factors of successful regional prevention of chlamydia and other STIs in Sweden.

Therefore, the specific aims were to:

- Map out the preventive response in seven Swedish counties in terms of structure and activities;

- Perform a case comparison of the counties to examine strengths and weaknesses compared to the standard preventive measures;
- Identify potential key factors of successful chlamydia prevention by examining strengths corresponding to high proportion of condom use and decreased number of chlamydia cases.

A conceptual model is presented in Figure 1, on which the framework of the case study was based.

\section{Methods}

\subsection{Case Selection}

In 2006, a new mutant variant of Chlamydia trachomatis bacteria (nyCT) was discovered, which was not identified by the nucleic acid amplification diagnostic tests (NAATs) vastly used in Sweden. Out of Sweden's 21 counties and regions, seven used the Becton Dickinson ProbeTec that detected the new variant. Hence this was used as selection criteria and the study was restricted to those counties, in the following named county A-G [20]. The counties were geographically distributed across the country, with varying population size (ranging from 127 thousand inhabitants in county B to 332 thousand in county E by December 2009), and varying proportions of youths (ranging from $17.9 \%$ in county A to $21.9 \%$ in county F by December 2009) [21].

\subsection{Data Collection}

The different sources for data collection were for prevention: survey, interviews and County Council records (2006-2009), for condom use: survey (2009), and for reported cases of chlamydia: national surveillance registers (2006-2009). Generally, the prevention of chlamydia and other STIs in Sweden is targeting youth (up to 18 years of age) and young adults (18 - 29 years of age).

\subsubsection{Survey}

In April 2010, a survey ${ }^{1}$ was sent by e-mail to two key informants in each county: STI-coordinators and CMOs. In some cases, surveys were passed on to colleagues within the Units for Communicable Disease Control (county CDC units) resulting in answers from STI-coordinators (all counties), four CMOs (counties B, E, F \& $\mathrm{G})$, and two CDC unit nurses (counties A \& D). The informants were selected for holding strategic positions in STI prevention from which they could take an overall view of the case. Before the questionnaires were sent out, the informants were informed by letter about the study and its aims. The questions in the survey considered prevention factors of structure corresponding to: program- and County Council investments, organizational structure, leadership, role in regional network, competencies, research connections, collaborations, regional action plans and implementation of NAP; and activity

${ }^{1}$ The survey is available as supplemental material. 


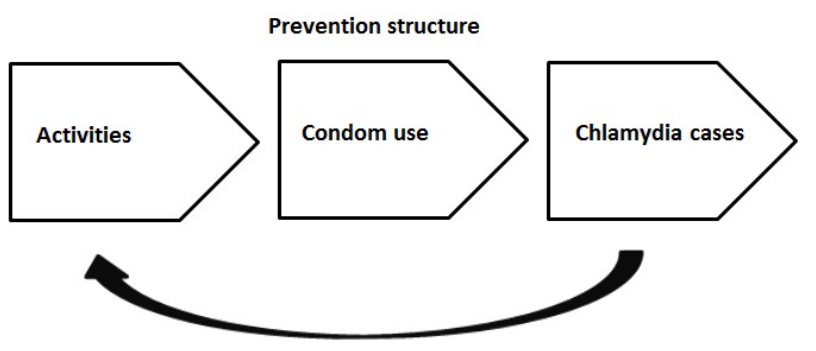

Figure 1. Conceptual model.

corresponding to: testing characteristics, testing coverage, partners tracing, risk approach, information efforts, internet based communication, outreaching activities and condom distribution.

\subsubsection{Interview}

Following the retrieval and reading of the completed surveys (received from all counties), telephone interviews with the 13 key informants were conducted during the period from April to June 2010. An additional five persons were interviewed based on recommendations by the original informants $(1 \mathrm{CDC}$ unit nurse in county $\mathrm{C}, 4$ counselors in STI-, dermatology- and venereology clinics in counties A, C, E and F). The purpose of this step was to further explore the preventive efforts and their implementation based on the same factors (structures and activities) as in the questionnaires. The answers from the interviews, which were audio recorded and ranged in length between 30 - 45 minutes, were condensed by county in a written document for all informants to read and comment on. This lead to a few additions and corrections in all cases, after which all informants, except one in county A that could not be reached after repeated attempts, approved.

\subsubsection{County Council Records}

The survey and interview data regarding prevention factors was complemented with County Council data regarding program investments from the governmental grant for prevention of STI (obtained from the counties' applications, decisions and follow-ups, and from statements of accounts on implemented projects), and County Council investments in STI prevention (obtained from County council records).

\subsubsection{Indicators of Successful Prevention}

Successful preventive response was indicated by high proportion of condom use (2009) and decreased number of chlamydia cases (2006-2009) for each county. The first indicator was measured by condom use at latest vaginal intercourse among youth and young adults 15 29 years, retrieved from a large survey study on young people, sex and health by Gothenburg University (Ung-
$\mathrm{KAB})[22]$. The survey was sent to a random selection of $15,000(15-29$ years) individuals across Sweden of which $77.5 \%$ answered the question on condom use at last intercourse (n 11,625). The second indicator was retrieved from the annual number of reported cases of chlamydia, provided by the Swedish Institute for Infectious Disease Control (SMI).

\subsection{Case Study Methodology}

The study was performed by the multiple case study method. Generally, this involves the use of multiple sources and techniques in the data gathering and analysing process in order to explore and generate understanding of a phenomenon based on a restricted number of cases [23]. Hence, the method was judged suitable for the current study aiming at exploring several prevention factors in connection to indicators of preventive success, among a selection of seven cases (counties), by various data sources.

\subsection{Analysis}

A single researcher performed the interviews while the analysis was done by two researchers to improve robustness. Each county was initially treated as a single case in the analyses of prevention data. Then, a cross-case search for patterns was applied to identify deviations from the norm of performance in prevention activities and structure [24].

In effect, a framework based on evidence from research was applied to the data from surveys and interviews in order to enable a rating system from $1-5$ for each prevention factor. The rating was data-based, meaning it was solely and consistently based on a comparison with other cases in the study. The performance of the majority of counties was referred to as the standard (3), whereas deviations were referred to as strengths (rating 4 - 5) and weaknesses (rating 1 - 2). Hence, the weakest performance on a prevention factor was given 1 while the strongest was given 5. For example, in program investment, county $\mathrm{F}$ was identified with the highest investment (5) while county B was found to have the second highest investment (4). Regarding testing characteristics, county B illustrated good accessibility with a campaign (4) while county $\mathrm{F}$ showed similar performance but with a more extensive strategic plan for testing, and was hence rated highest (5). Potential key factors for successful prevention were finally identified by strengths (4 - 5) corresponding to a high proportion of condom use and a decrease in number of reported chlamydia cases.

The study was approved by the Research Ethics Committee at Karolinska Institutet in March 2010 (Dnr: 2010/239-31/4). 


\section{RESULTS}

\subsection{Strengths and Weaknesses in Chlamydia Prevention}

The summarised results of the analyses of prevention data from survey and interviews for each county are presented in Tables $\mathbf{1}$ (structure) and $\mathbf{2}$ (activities).

County A-On the structural level most factors ( 7 of 10) were found below the standard, with weaknesses regarding structure of organization, leadership, competencies, research connection, collaborations, regional action plan and implementation of NAP. Concerning activities, 2 of 8 factors were on a standard level while weaknesses (6 of 8 ) regarded testing coverage, partner tracing, risk approach, information efforts, internet based communication and outreaching activities. No strengths were found.

County B-Most of the structural factors (7 of 10) were identified on a standard level, although identified strengths ( 2 of 10) concerned high program investment and a regional action plan. On the other hand, one weakness was found to be a saving package in the County Council. Regarding activities, factors of strength (4 of 8) were testing characteristics, information efforts, outreaching activities and condom distribution. Weaknesses ( 3 of 8 ) were found for testing coverage, partner tracing and risk approach, whereas regarding internet based communication, the county corresponded to standard preventive measures.

County C-Most structural factors (6 of 10) were identified on a standard level, one strength was identified (County Council investment), while weaknesses (3 of 10) were recognized in program investment, competencies and research connection. Also for activities, the majority was on a standard level ( 7 of 8$)$. The exception was the weakness of restricted information efforts.

County D-Regarding structural factors, the county was mainly in line with standard ( 8 of 10 ) with strength in implementation of NAP and a weakness regarding organization structure. Concerning activities, strengths

Table 1. Structure of prevention: strengths $(4,5)$ and weaknesses $(1,2)$ compared to standard (3) in seven Swedish counties (A-G).

\begin{tabular}{|c|c|c|c|c|c|c|c|}
\hline Data Cases & $A$ & B & C & $D$ & E & $F$ & G \\
\hline $\begin{array}{l}\text { Program } \\
\text { investment }\end{array}$ & (3) & Rather high (4) & Low (1) & (3) & (3) & High (5) & Rather low (2) \\
\hline $\begin{array}{l}\text { County council } \\
\text { investment }\end{array}$ & (3) & $\begin{array}{c}\text { Saving package } \\
\text { (1) }\end{array}$ & Favourable (4) & (3) & (3) & High (5) & Tight budget (2) \\
\hline $\begin{array}{l}\text { Organization } \\
\text { structure }\end{array}$ & $\begin{array}{c}\text { STI-group meet } \\
\leq 3 \text { times/year }(1)\end{array}$ & (3) & (3) & $\begin{array}{l}\text { STI-group meet } \\
\leq 4 \text { times/year (2) }\end{array}$ & $\begin{array}{l}\text { STI-group meet } \\
6-8 \text { times/year } \\
\text { (4) }\end{array}$ & $\begin{array}{l}\text { STI-group meet } \\
\geq 6 \text { times/year, } \\
\text { Network } \\
\text { meetings }(5)\end{array}$ & (3) \\
\hline Leadership & $\begin{array}{l}\text { STI-coordinator } \\
20 \%(1)\end{array}$ & (3) & (3) & (3) & $\begin{array}{c}\text { Good } \\
\text { leadership (4) }\end{array}$ & $\begin{array}{l}\text { Strong \&clear } \\
\text { leadership (5) }\end{array}$ & $\begin{array}{l}\text { No STI-coordinator, } \\
\text { Good leadership (2) }\end{array}$ \\
\hline $\begin{array}{l}\text { Role regional } \\
\text { network }\end{array}$ & (3) & (3) & (3) & (3) & Responsible (4) & Responsible (4) & (3) \\
\hline Competencies & Little training (1) & (3) & $\begin{array}{l}\text { Restricted } \\
\text { training (2) }\end{array}$ & (3) & (3) & $\begin{array}{l}\text { Extensive MI } \\
\text { training, High } \\
\text { education to } \\
\text { health care \& } \\
\text { school staff (4) }\end{array}$ & $\begin{array}{l}\text { Extensive MI training, } \\
\text { High education to } \\
\text { health care \& youth } \\
\text { contexts, Innovative } \\
\text { training (5) }\end{array}$ \\
\hline $\begin{array}{l}\text { Research } \\
\text { connection }\end{array}$ & $\begin{array}{l}\text { None mentioned } \\
\text { (1) }\end{array}$ & (3) & $\begin{array}{c}\text { None } \\
\text { mentioned, } \\
\text { Systematic } \\
\text { evaluation (2) }\end{array}$ & (3) & $\begin{array}{l}\text { Strong \& broad } \\
\text { (5) }\end{array}$ & Strong (4) & (3) \\
\hline Collaborations & $\begin{array}{l}\leq 3 \text { regional agents } \\
\text { (2) }\end{array}$ & (3) & (3) & (3) & $\begin{array}{l}\geq 5 \text { regional } \\
\text { agents (4) }\end{array}$ & $\begin{array}{l}\geq 7 \text { regional } \\
\text { agents }(5)\end{array}$ & $\leq 2$ regional agents $(1)$ \\
\hline $\begin{array}{l}\text { Regional action } \\
\text { plan }\end{array}$ & $\begin{array}{l}\text { No measurable } \\
\text { goals (2) }\end{array}$ & $\begin{array}{l}\text { Extensively } \\
\text { developed, } \\
\text { Measurable } \\
\text { goals (4) }\end{array}$ & (3) & (3) & (3) & $\begin{array}{l}\text { Extensively } \\
\text { developed, } \\
\text { Measurable } \\
\text { goals, In line } \\
\text { with NAP (5) }\end{array}$ & From 2009 (1) \\
\hline $\begin{array}{l}\text { Implementation } \\
\text { of NAP }\end{array}$ & Not actively (1) & (3) & (3) & Continuously (4) & (3) & $\begin{array}{l}\text { Extensively } \\
\text { (5) }\end{array}$ & $\begin{array}{l}\text { Actively from } 2009 \\
\text { (2) }\end{array}$ \\
\hline
\end{tabular}


Table 2. Activities of prevention: strengths $(4,5)$ and weaknesses $(1,2)$ compared to standard (3) in seven Swedish counties (A-G).

\begin{tabular}{|c|c|c|c|c|c|c|c|}
\hline Data Cases & A & $B$ & C & $D$ & $E$ & $F$ & G \\
\hline $\begin{array}{c}\text { Testing } \\
\text { characteristics }\end{array}$ & (3) & $\begin{array}{l}\text { Paid by central } \\
\text { account, Good } \\
\text { accessibility, } \\
\text { Campaign (4) }\end{array}$ & (3) & $\begin{array}{l}\text { Paid by test } \\
\text { taking unit, } \\
\text { Rather poor } \\
\text { accessibility, No } \\
\text { campaign (1) }\end{array}$ & (3) & $\begin{array}{c}\text { Paid by central account, } \\
\text { Good accessibility, } \\
\text { Extensive strategy (5) }\end{array}$ & (3) \\
\hline $\begin{array}{l}\text { Testing } \\
\text { coverage }\end{array}$ & $\begin{array}{l}\text { Low } \\
\text { male/female } \\
\text { ratio \& test per } \\
\text { case }(2)\end{array}$ & $\begin{array}{l}\text { Low male/female } \\
\text { ratio, test/case \& } \\
\text { test } / 100000 \\
\text { inhabitants (1) }\end{array}$ & (3) & (3) & $\begin{array}{l}\text { High male/female } \\
\text { ratio, test/case \& } \\
\text { test } / 100,000 \\
\text { inhabitants (5) }\end{array}$ & $\begin{array}{l}\text { High male/female ratio } \\
\& \text { test } / \text { case } \& \text { moderate } \\
\text { test } / 100,000 \\
\text { inhabitants }(4)\end{array}$ & $\begin{array}{c}\text { No } \\
\text { male/female } \\
\text { ratio, low } \\
\text { test } / \text { case \& } \\
\text { test } / 100,000 \\
\text { inhabitants (1) }\end{array}$ \\
\hline Partner tracing & $\begin{array}{l}\text { Decentralized, } \\
\text { Little quality } \\
\text { assurance (1) }\end{array}$ & $\begin{array}{l}\text { Decentralized, } \\
\text { Moderate quality } \\
\text { assurance (2) }\end{array}$ & (3) & $\begin{array}{l}\text { Centralized, } \\
\text { Quality assured, } \\
1 \text { year back in } \\
\text { time, Research } \\
\text { (4) }\end{array}$ & (3) & $\begin{array}{l}\text { Centralized, Quality } \\
\text { assured, } 1 \text { year back in } \\
\text { time Research (5) }\end{array}$ & (3) \\
\hline Risk approach & $\begin{array}{l}\text { MI for risk } \\
\text { patients (2) }\end{array}$ & Poor MI use (1) & (3) & (3) & $\begin{array}{l}\text { Strategies, } \\
\text { Consistent MI use } \\
\text { some clinics (4) }\end{array}$ & $\begin{array}{l}\text { Risk assessment tools } \\
\& \text { strategies, Consistent } \\
\text { MI use (5) }\end{array}$ & (3) \\
\hline Information efforts & Little (1) & Extensive (4) & $\begin{array}{l}\text { Restricted } \\
\text { (2) }\end{array}$ & (3) & (3) & $\begin{array}{l}\text { Extensive through } \\
\text { variety of channels (5) }\end{array}$ & (3) \\
\hline $\begin{array}{l}\text { Internet based } \\
\text { communication }\end{array}$ & None (1) & (3) & (3) & $\begin{array}{l}\text { Several online } \\
\text { activities (4) }\end{array}$ & Little (2) & $\begin{array}{l}\text { A range of online } \\
\text { activities (5) }\end{array}$ & (3) \\
\hline $\begin{array}{l}\text { Outreaching } \\
\text { activities }\end{array}$ & Some (2) & Extensive (4) & (3) & (3) & (3) & $\begin{array}{l}\text { Extensive in range of } \\
\text { settings (5) }\end{array}$ & Few (1) \\
\hline $\begin{array}{l}\text { Condom } \\
\text { distribution }\end{array}$ & (3) & $\begin{array}{c}\text { Extensive \& } \\
\text { systematic (5) }\end{array}$ & (3) & Few (2) & (3) & Extensive (4) & No data (1) \\
\hline
\end{tabular}

were found ( 2 of 8 ) regarding partner tracing and internet-based communication. Four factors were on standard level, while testing characteristics and condom distribution were identified as weaknesses.

County E-The distribution of strength and standard factors on a structural level was equal for the county ( 5 of 10 respectively). Strengths included the organization structure, leadership, the managing role in the regional network, research connection and collaborations. Considering activities, 5 out of 8 factors corresponded to the standard preventive measures, whereas testing coverage and risk approach were judged as strengths, and internet based communication as a weakness.

County F-The county was defined the strongest case with all structural (10 of 10) and activity factors (8 of 8 ) identified as strengths. Seven out of ten structural, and six out of eight activity components were rated at highest level (5) for possible strengths.

County $G$-The identified strength in structural factors for the county was competencies while other factors were on the standard level (3 of 10) or identified as weaknesses (6 of 10). Concerning activities, most factors corresponded to the standard level (5 of 8), while testing coverage, outreaching activities and condom distribution
(3 of 8) were rated as weaknesses.

In summary, county $\mathrm{F}$ was the only county identified with strengths in all prevention factors and county $\mathrm{E}$ was the only county found to hold only strengths and components at standard level with the exception of internet based communication. On the other hand, county A was the only county without classified strengths, with only weaknesses besides standard preventive measures. Also county $\mathrm{G}$ had more weaknesses than strengths identified along with factors on the standard level.

\subsection{Indicators of Preventive Success}

Figure 2 shows the proportion of condom use by county. In counties $\mathrm{C}, \mathrm{E}$ and $\mathrm{F}$, the use of condom at last intercourse among youth and young adults were $29 \%$, $26.5 \%$ and $27.6 \%$, respectively, while in other counties the use was lower, spanning from $17.8 \%-23.0 \%$.

Figure 3 shows variations in number of reported cases of chlamydia between counties. During the period from year 2006 to 2007, most counties (A, D, E, F \& G) experienced an increase, whilst during 2008 to 2009, most counties experienced a decrease (A, C, D, E, F \& G). Regarding the whole period (2006-2009), county F had 


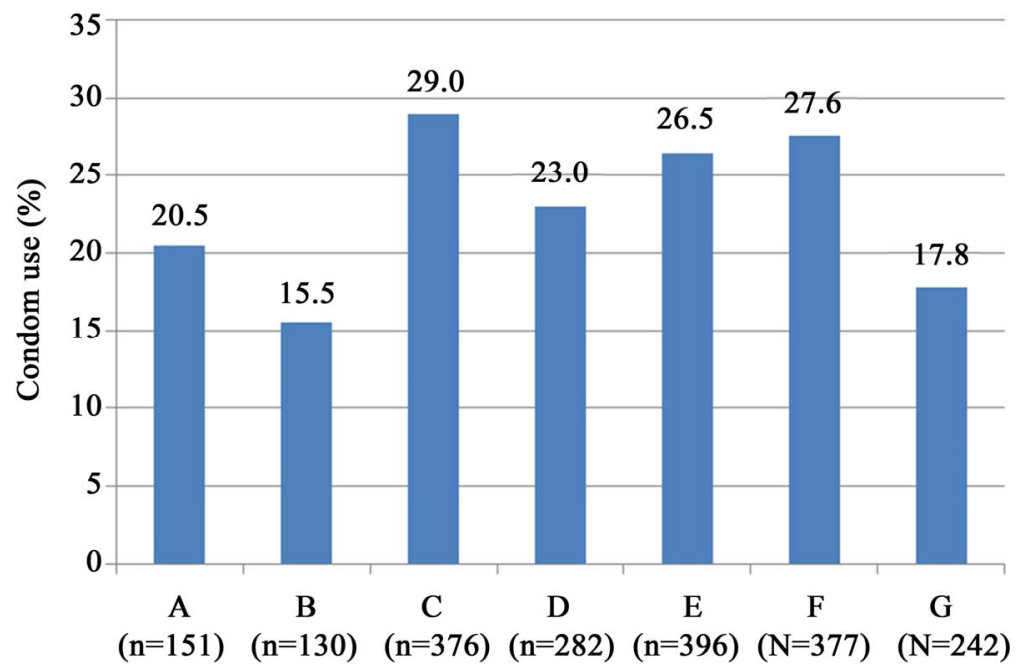

Figure 2. Proportion of condom use at last vaginal intercourse by county in 2009 (Source: UngKAB).

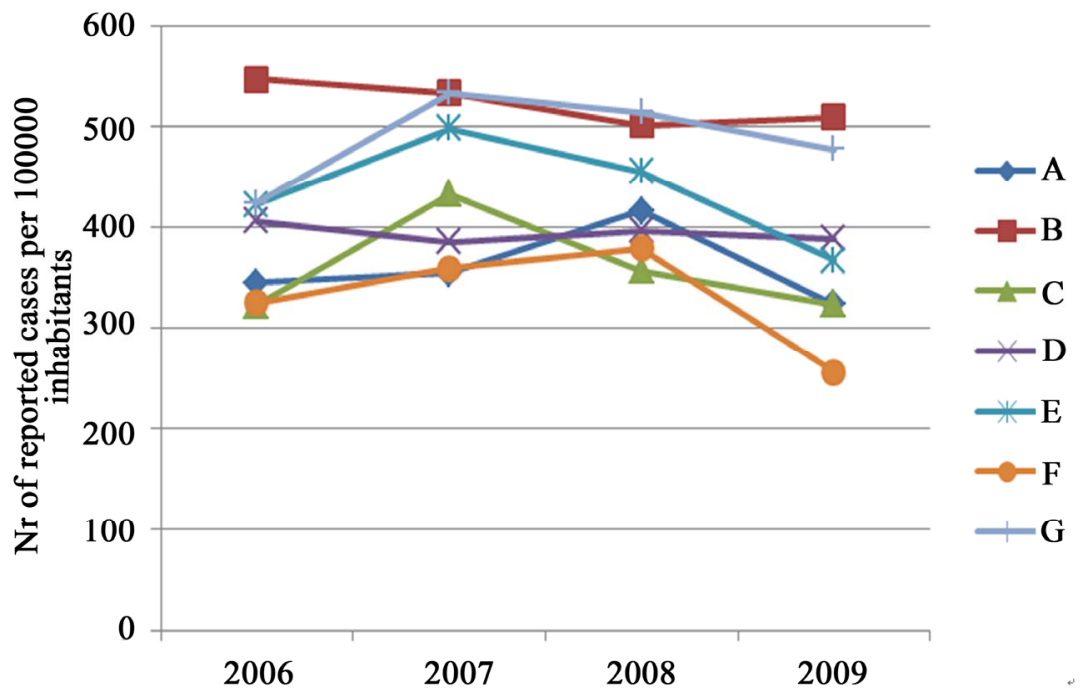

Figure 3. Number of reported cases of chlamydia per 100,000 inhabitants from 2006 to 2009 (Source: Swedish Institute of Infectious Disease Control).

the strongest decrease in reported number of chlamydia cases by $21.03 \%$, whereas counties A, B, D and E had moderate decreases $(5.55 \%, 7.05 \%, 5.28 \%$ and $9.84 \%)$.

The conclusion is that two counties (E and F) fulfil the indication of successful prevention based on the combined consideration of high proportion of condom use and decreased number of reported chlamydia cases.

\subsection{Key Factors of Successful Prevention of Chlamydia}

The identification of potential key factors of successful prevention against chlamydia and other STIs is based on assessed prevention strengths 2006-2009 (county F held strengths in all factors, and county E held strengths or standard preventive measures except for internet based communication) in relation to the indicator of successful prevention (counties $\mathrm{E}$ and $\mathrm{F}$ illustrated high condom use (2009) as well as a reduction of chlamydia cases (20062009)). Counties $E$ and $F$ were also the counties with the highest proportions of young people compared to other counties $(21 \%-22 \%$ versus $18 \%-19 \%)$.

County F deviated from the rest of the counties with a combination of high investments via the governmental grant (program investment) and high investments in, not only STI prevention, but also general public health and health care issues via the County Council. This generated a need-based and flexible resource allocation where the CMO and the STI-coordinator had the possibility to initiate prevention activities where and when a need was identified. 
Strengths in collaboration and organization were evident for counties $\mathrm{E}$ and $\mathrm{F}$, as well as in their position as responsible of managing the regional networks for STI prevention that all counties are involved in. Both counties also represented strengths regarding the number of collaborating partners, and regarding research and performance of research projects. Concerning leadership and competencies, four counties including $\mathrm{E}$ and $\mathrm{F}$ had STI-coordinators in full time position, which in all cases were recognised as a crucial prerequisite for the coordination and structured implementation of activities. Additionally, counties $\mathrm{E}$ and $\mathrm{F}$ showed favourable testing coverage, with the highest ratios of tested males versus females, high number of tests per case and high number of tests per 100,000 inhabitants of $15-29$ years old (2008 and 2009). County $F$ had also the highest number of tests per positive case (2008 and 2009).

Contrasting counties E and F, E had a more traditional approach while $\mathrm{F}$ applied more innovative activities regarding, for example, information and communication efforts. County F differentiated itself by the use of approaches such as theatre shows, and information tours at youth clubs, while the majority of counties use strategies such as information by outreach to schools. It could be that this, in combination with other outreaching activities, maintained the awareness of the issue among youth in the region. County $\mathrm{F}$ provided also a range of online platforms for communication with the target group via information sites for events and competitions, condom sites for information and distribution, online tools for booking appointments and internet-based testing possibilities.

Two counties, A and G appeared to be characterized by several weaknesses. County A stands out in that it performed few prevention activities together with weaknesses on the structural level such as having little collaboration, less than three STI-groups meetings per year and a limited engagement by a STI-coordinator. The weaknesses were combined with low condom use, but also with a decrease of reported chlamydia cases $(5.55 \%$ from 2006 to 2009). When assessing this situation, it must be considered that county A had the most significant decrease in testing of all counties (19.63\% from 2008 to 2009). County $G$ had weaknesses such as poor investments, collaboration and testing coverage. Furthermore, up until year 2009 the county had neither a STI-coordinator nor a regional action plan. The identified weaknesses were correlated with low condom use and increased number of reported chlamydia cases (4.27\% from 2006-2009).

County $\mathrm{B}$ received high ratings in prevention activities, but experienced a moderate decrease in reported chlamydia cases (2006-2009). This county receives high numbers of tourists and young seasonal employees during the winter season, which contributes to a high proportion of cases in individuals residing outside the county, potentially not targeted by the prevention activities in the county.

County D was found to correspond to the standard preventive measures in structure and strengths of partner tracing and internet-based communication were found in activities. This was combined with a moderate decrease in chlamydia cases [24]. County D is the largest of the counties with long distances between towns and clinics, which has been responded to by a system of telephone based partner tracing.

County $\mathrm{C}$ experienced a slight increase in reported cases, despite prevention efforts similar to other counties and the highest condom use of all (29.0\%). This should also be considered in the light of having the highest proportion of individuals stating that religion affects their everyday life very much, $4.6 \%$ compared to $2.4 \%$ in Sweden in general [22].

\section{DISCUSSION}

\section{Main Findings}

The present study was performed to identify potential key factors of successful chlamydia prevention by a multiple case study, analysing the differences between Swedish counties in prevention efforts (2006-2009), condom use (2009) and decrease of reported chlamydia cases (2006-2009). To the authors' knowledge, it is the first study to explore this area. Identified potential key factors were: adequate program- and County Council investments, suitable organizational structure, strong leadership, managing regional networks, research connection, multiple local collaboration, high testing coverage and strategic risk approach. In all, counties with strengths in preventive measures were $\mathrm{E}$ and $\mathrm{F}$, counties with weaknesses were $A$ and $G$, and counties with standard preventive measures were $\mathrm{B}, \mathrm{C}, \mathrm{D}$.

More specifically, high investments in primary and secondary prevention, legitimate and clear leadership and collaboration with multiple cross-sectional regional agents, and scientific foundation for action seemed vital. Furthermore, comprehensive testing with high ratios of tested men versus women, high numbers of tested per positive case and of tested per 100,000 inhabitants were identified as important. Finally recognised as successful was implementing a broad mix of efforts simultaneously, including targeting risk individuals in testing and counseling, and potentially using innovative approaches like internet-based communication and health care services.

Investment levels in STI prevention activities in county $\mathrm{F}$ were significantly higher per capita than in the other counties and increased investments have been made from the County Council. Considering the high 
proportion of condom use and reduction in chlamydia cases in this county, this highlights availability of resources as a key factor in an active response complementary to increasing needs in the population. Earlier research states that a good balance between spending on prevention, health promotion, and treatment care is favourable [7,9]. In the case of county $F$, this may be reflected by the program investment (prevention) and spending by County Council (traditionally testing, treatment and partner tracing).

Counties $\mathrm{E}$ and $\mathrm{F}$ received funding from and were responsible for the governmental grant for the regional networks, which may entail a possible synergetic effect regarding leadership, capacity and knowledge. However, whether this brings positive effects or whether the latter was a factor in them being assigned the responsibility is unknown.

The organizational structure in county $\mathrm{F}$ indicates that many local agents and multiple institutions in collaboration may benefit the outcome of activities. Further, a strong leadership and clear goals were identified, and also expressed by informants, as strengths. This supports evidence concerning the importance of building and sustaining partnerships including NGO's, health care practitioners and researchers [8].

Accessibility to testing and quality-assured partner tracing with trained partner tracers were important strategies for all counties although the execution varied in terms of county covering policies. The situation in county $\mathrm{F}$ indicates that actively attempting to target risk groups with risk assessment tools and consistent behavioural counseling methods at the time of testing, may be effective [8] along with quality-assured partner tracing [25], centralized to a limited number of trained partner tracers. The fact that county $\mathrm{E}$ and $\mathrm{F}$ show high numbers in testing volumes, testing ratio of males versus females and number of tests per case indicates that they have succeeded in reaching risk groups. This, in combination with their high condom use and decrease in reported chlamydia cases indicates that a targeted and comprehensive testing profile is a sound approach and that men are then included in testing to a greater extent. In counties $C, D$ and $G$, testing is paid for by the specific test-taking unit, which could be questioned as contradictory with the aim of establishing a sustainable and volume-independent testing profile.

Counties C, D and F use the internet as a platform for communication with the target group in many of their activities regarding information, condom distribution and testing. Previous studies highlight the preventive potential of internet-based communication with target groups that seek health information online, specifically on sex and sexuality in general, [26] and for chlamydia testing $[27,28]$.
Regional differences in population size of young people across counties confirm that prevention efforts in county $\mathrm{E}$ and $\mathrm{F}$ were well suited to the target group of chlamydia and other STIs, that county B despite fine prevention efforts failed to reach the large group of seasonal employees, that county A managed to compensate weak prevention efforts with low proportion of young people, and that county $\mathrm{C}$ had high condom use and a slight decrease in chlamydia cases despite standard prevention measures.

\section{LIMITATIONS}

The study does not consider the effectiveness of certain prevention factors, but merely relates the results to current evidence on effective STI prevention. Nor does it attempt to clarify the causal link between prevention structure, prevention activities, condom use and reported cases of chlamydia. Another evident limitation is the general difficulties regarding the outcome of chlamydia since the spread of infectious disease will ultimately depend on many different factors.

Condom use as a risk measurement of STI was considered a suitable indicator of successful prevention. It is worth noting that previous studies have shown that condom use among Swedish adolescents and young adults is relatively low (20\%) compared with Finland (48\%) and Norway (55\%) [29] and other European countries. The UngKab survey was not powered with the aim of detecting between-counties differences of condom use, and the variation in numbers of respondents between counties may be due to differences in population size as well as in response rate. This weakness was, however, considered acceptable considering that there is no other currently available data that could serve as an indicator of condom use by county in Sweden.

The decrease in number of reported chlamydia cases was considered the ultimate indicator of chlamydia prevention. However, this is merely an indicator of prevalence (and incidence) of disease. While the true incidence can only be identified if general screening is in place, the number of reported cases largely depends on surveillance systems and the fulfilment of reported cases may vary between laboratories, health care staff and counties. It should also be noted as limitation that all cases with a decrease in reported cases was considered noteworthy. In the analysis, based on the combined consideration of high proportion of condom use and decreased number of chlamydia cases, the two counties (E and $\mathrm{F}$ ) with a decrease greater than $9 \%$ were concluded to constitute the joint indication of successful prevention. However, the only county with a statistically significant decrease $(\mathrm{p}<0.05)$ during the study period was F. Furthermore, nationally covered data on age- and sex-specific testing volumes and frequencies are not available 
due to the characteristics of the current reporting systems in Sweden.

In the analysis, preventive factors were regarded as equal, given the same value regardless of whether, for example, a quality assured and well-functioning partner tracing is more decisive for success than condom distribution. It should also be noted that comprehensive data on the quality and quantity of sexual education activities in schools have not been taken into consideration. Given the health promotion evidence for such interventions, [19] one cannot exclude a possible distorting impact on the results.

It must be acknowledged, as a potential limitation, that county F's CMO was involved in the development of the National Action Plan for chlamydia prevention 2009 together with the Swedish National Board of Health and Welfare. This indicates that county F has had the opportunity to regionally implement the NAP ahead of time in comparison to the other counties. Moreover, it is quite probable that participation in the national goal setting and planning facilitate regional strategy setting and implementation [2].

The study generally supports a link between on the one hand preventive strengths and on the other hand high condom use and decreased chlamydia cases. However, the situation in counties B, C and D displays that the present case study application is not sufficient for a deeper understanding of the underlying complex regional characteristics such as seasonal migration, geographic distances and other demographic/cultural factors.

Nevertheless, the advantage of the case study method is its applicability to contemporary, situational cases, based on multiple sources of data which reinforce findings through triangulation [30]. In this study, survey and interviews among key informants, and regional and national registry data, regarding seven counties were used. Rich amounts of data for analysis and conclusion is a strength, while the risk of missing vital components in the mass of data and of failing to clearly structure analysis and conclusion is a weakness. Considering the heterogeneity of the studied cases and the extensive sources of information used, the present study is likely to add knowledge on potential key factors in regional prevention of chlamydia and other STIs. Despite several limitations, we suggest that it provides insight into current activities as well as into development needs.

\section{CONCLUSION}

This study concludes that Swedish counties implement a range of similar prevention efforts in the area of chlamydia and other STIs, but that the scope and systematization of implementation differs. The national as well as the regional action plans show little concern for the structure of prevention. Greater consideration to struc- tural factors, such as adequate investments, suitable organizational structure, strong leadership, regional networks, research connection and multiple local collaboration may therefore benefit the outcomes of prevention activities. However, in order to confirm our findings, further studies of successful prevention mix are required and research bridging the gap between STI-prevention and infectious disease epidemiology should be encouraged.

\section{ACKNOWLEDGEMENTS}

The financial support of The Swedish National Board of Health and Welfare is gratefully acknowledged.

\section{REFERENCES}

[1] (2012) Swedish Institute of Infectious Disease Control [Online].

http://www.smittskyddsinstitutet.se/statistik/klamydiainfe ktion/

[2] Swedish National Board of Health and Welfare (2012) National action plan for chlamydia prevention. http://www.socialstyrelsen.se/Lists/Artikelkatalog/Attach ments/8402/2009-126-180 2009126181.pdf

[3] DuRant, R.H., Smith, J.A., Kreiter, S.R. and Krowchuk, D.P. (1999) The relationship between early age of onset of initial substance use and engaging in multiple health risk behaviors among young adolescents. Archives of Pediatrics \& Adolescent Medicine, 153, 286-291.

[4] Hansen, B.T., Kjaer, S.K., Munk, C., et al. (2010) Early smoking initiation, sexual behavior and reproductive health-A large population based study of Nordic women. Preventive Medicine, 51, 68-72.

doi:10.1016/j.ypmed.2010.03.014

[5] Deogan, C., Cnattingius, S. and Månsdotter, A. (2012) Risk of self-reported Chlamydia trachomatis infection by social and lifestyle factors-A study based on survey data from young adults in Stockholm, Sweden. European Journal of Contraception and Reproductive Health Care, in Press. doi:10.3109/13625187.2012.729624

[6] Ellis, S. and Grey, A. (2004) Prevention of sexually transmitted infections (STIs): A review of reviews into the effectiveness of non-clinical interventions. Evidence briefing. Health Development Agency, London.

http://www.nice.org.uk/nicemedia/documents/prevention stis evidence briefing.pdf

[7] National Institute for Health and Clinical Excellence (2007) Public health intervention guidance 3. One to one interventions to reduce the transmission of sexually transmitted infections (STIs) including HIV, and to reduce the rate of under 18 conceptions, especially among vulnerable and at risk groups. National Institute for Health and Clinical Excellence, London.

http://www.nice.org.uk/Guidance/PH3/Guidance/pdf/Eng $\underline{\text { lish }}$

[8] Bernard, D., Kippax, S. and Baxter, D. (2008) Effective partnership and adequate investment underpin a success- 
ful response: Key factors in dealing with HIV increases. Sexual Health, 5, 193-201. doi: $10.1071 / \mathrm{SH} 07078$

[9] Griew R. (2008) Policy and strategic implications of Australia's divergent HIV epidemic among gay men. Sexual Health, 5, 203-205. doi:10.1071/SH08003

[10] Farley, C., Grulich, A., Imrie, J. and Pitts, M. (2008) Investment in HIV prevention works: A natural experiment. Sexual Health, 5, 207-210. doi:10.1071/SH08017

[11] Miller, R.L., Bedney, B.J. and Guenther-Grey, C. (2003) Assessing organizational capacity to deliver HIV prevention services collaboratively: Tales from the field. Health Education \& Behavior, 30, 582-600. doi:10.1177/1090198103255327

[12] Sylvan, S. and Hedlund, J. (2009) Efficacy of partner notification for Chlamydia trachomatis among young adults in youth health centres in Uppsala County, Sweden. Journal of the European Academy of Dermatology and Venereology, 23, 517-522. doi:10.1111/j.1468-3083.2008.03080.x

[13] Lin, J.S., Whitlock, E., O’Connor, E. and Bauer, V. (2008) Behavioural counseling to prevent sexually transmitted infections: A systematic review for the US. Preventive Services Task Force. Annals of Internal Medicine, 149, 497-508.

[14] Löfdahl, M., Rydevik, G., Blaxhult, A. and Hermann, B. (2008) Chlamydia infection among Swedish women. Contact tracing and reporting routines must be improved. Läkartidningen, 105, 3116-3120.

[15] Kamb, M.L., Fishbein, M., Douglas, J.M., et al. (1998) Efficacy of risk-reduction counseling to prevent human immunodeficiency virus and sexually transmitted diseases. Journal of the American Medical Association, 280, 1161-1167.

[16] Petersen, R., Albright, J., Garrett, J.M. and Curtis, K.M. (2007) Pregnancy and STD prevention counseling using an adaptation of motivational interviewing: A randomized controlled trial. Perspectives on Sexual and Reproductive Health, 39, 21-28. doi:10.1363/3902107

[17] Outlaw, A.Y., Naar-King, S., Parsons, J.T., Green-Jones, M., Janisse, H. and Secord, E. (2010) Using motivational interviewing in HIV field outreach with young African American men who have sex with men: A randomized clinical trial. American Journal of Public Health, 100, 146-151. doi:10.2105/AJPH.2009.166991
[18] Scmeidl, R. (2004) School-based condom availability programs. The Journal of School Nursing, 20, 16-21. doi:10.1177/10598405040200010401

[19] Oakley, A., Fullerton, D., Holland, J., France-Dawson, M., Kelley, P. and McGrellis, S. (1995) Sexual health educations interventions for young people: A methodological review. British medical Journal, 310, 158-162. doi:10.1136/bmj.310.6973.158

[20] Velicko, I., Kühlmann-Berenzon and Blaxhult, A. (2007) Reasons for the sharp increase of genital chlamydia infections reported in the first months of 2007 in Sweden. Eurosurveillance, 12, E5-E6.

[21] (2011) Statistics Sweden [Online] http://www.scb.se/default 2154.aspx

[22] UngKAB09 (2009) Department of Social Work, Gothenburg University.

[23] Yin, R.K. (2009) Case study research. Design and methods. SAGE Publications, Inc., Thousand Oaks.

[24] Stake, R.E. (2006) Multiple case study analysis. The Guilford Press, New York.

[25] Carré, H., Boman, J., Gardén, B. and Nylander, E. (2008) Improved contact tracing for Chlamydia trachomatis with experienced tracers, tracing for one year back in time and interviewing by phone in remote areas. Sexually Transmitted Infections, 84, 239-242. doi:10.1136/sti.2007.028068

[26] Hassan, A. and Fleegler, E.W. (2010) Using technology to improve adolescent health care. Current Opinion in Pediatrics, 22, 412-417. doi:10.1097/MOP.0b013e32833b5360

[27] Rainton, N., Odegard, O.R., Helgheim, A. and Moghaddam, A. (2007) Detection of chlamydia infection of an internet-based commercial product. Tidskr Nor Laegeforen, 127, 2080-2082.

[28] Stenqvist, K., Lindqvist, A., Almerson, P., Jonsson, L. and Lander, R. (2010) Chlamydia test via internet a good alternative to testing in clinics. Läkartidningen, 107, 350353.

[29] (2012) Norwegian Ministry of Health. http://helsedirektoratet.no/english/publications/ungass-coun try-progress-report-norway-january-2008---december-200 9/Publikasjoner/ungass-conuntry-progress-report-norway2009.PDF

[30] Malterud, K. (2001) Qualitative research: Standards, challenges and guidelines. Lancet, 358, 483-488. 


\section{SUPPLEMENTAL MATERIAL}

\section{Survey}

1) Organization, contact person, email, phone number

2) Is the national action plan actively implemented?

-Is there already existing activities that are in line with the national action plan?

3) What preventive measures aimed at STI/chlamydia have been implemented from 2006-2009 in the county?

-How long have the efforts been ongoing?

-What organizations are responsible of the efforts?

-Scope/extent of each activity? Target groups/populations? Geographic restriction/area limitation?

-Is there condom distribution? (Scope, what arenas and who is responsible?)

-Is there testing via internet? What proportions of the tests taken in the county are taken via the Internet?

-Are there outreaching activities?

-Are there reoccuring campaigns or other activities to promote testing?

-Has the work been evaluated in reference to the action plan?

4) Describe the organization and structure of the preventive work.

-Collaboration at planning level?

-Collaboration in implementing activities?

-Are there targets/goals for prevention activities? How are the goals formulated?

-Is there a regional steering group? What functions/ professions/mandates are included? How often does the group meet?

-Are there regional steering documents? (Please attach them to the questionnaire or provide the website)

-At what level are results reported? Are the effects of efforts measured or evaluated?

5) Are seminars or information sessions offered internally in the organization regarding STI-development?
If so, is it offered to;

-Health care staff?

-School staff?

-Other staff that work with the target group?

-(Please specify the scope of the sessions)

6) How much resources were allocated to prevention activities during 2006-2009? How would you describe the economic situation in the county council?

-What positions would you say allocate their time to prevention activities?

-What tasks are included in these positions?

-Scope of the positions (full/part time)?

-Material, PR?

7) What are the routines regarding testing?

-Methods, techniques?

-Is there a standardized guide for testing? (Who should be tested? What type of test is recommended for men versus women?)

-Are laboratory notifications and clinical notifications control-checked for double samples? If clinical notification is missing, is it asked for?

8) What are the routines regarding contact tracing?

-Who performs contact tracing?

-According to guidelines?

-Are contacts traced 1 year back in time?

-Average time/patient?

-Is counseling offered? If so, what kind of counseling? Individually or in group?

-Is there specific training for contact tracers and if so, how is the training performed, by whom and for how long time?

-Are there any actions taken if contact tracing is not performed?

9) What is your opinion of the National Action Plan?

10) What do you think about the chlamydia development in your county? In your opinion, what are the underlying reasons for the development? 